\section{Adventitious Shoot Formation on Excised Hypocotyls of Antirrhinum majus L. (Snapdragon) In Vitro}

\author{
Kenneth R. Schroeder ${ }^{1}$ and Dennis P. Stimart ${ }^{2}$ \\ Department of Horticulture, University of Wisconsin, 1575 Linden Drive, \\ Madison, WI 53706-1590 \\ Additional index words. micropropagation, tissue culture, regeneration, organogenesis, \\ caulogenesis, light, cytokinin, genotype, seedling age
}

\begin{abstract}
Hypocotyls from Antirrhinum majus L. were excised at 2 weeks of age from seedlings grown under a 16-hour photoperiod or continuous darkness. Explants were cultured on modified Murashige-Skoog (MS) medium containing $0,0.44,2.22,4.44,8.88$, or $44.4 \mu_{\mathrm{M}} \mathrm{BA}$ to investigate adventitious shoot formation. Excised hypocotyls from eight commercial cultivars, three inbred lines, and an $F_{1}$ hybrid between two of the inbreds were cultured on MS medium containing $2.22 \mu_{\mathrm{M}} \mathrm{BA}$ to assess genotypic effects on adventitious shoot formation. The influence of seedling age was assessed by excising hypocotyls from seedlings at 6, 10, 14, 18, 22, 26, or 30 days. Optimal conditions for adventitious shoot formation on excised hypocotyls included: seedling growth in a lighted environment, use of hypocotyls from 10-day-old seedlings, and culture on medium containing $2.22 \mu \mathrm{M}$ BA for 3 weeks. Under these conditions, up to a 5 -fold improvement in number of shoots per hypocotyl over previous studies was achieved. Adventitious shoot formation was genotype-dependent and appeared to be a dominant trait. Chemical name used: $N^{6}$-benzyladenine (BA).
\end{abstract}

Antirrhinum majus is important commercially as a cut flower, annual bedding plant, and potted plant. It is used widely as a model for genetic studies of floral development (Coen et al., 1990), floral pigmentation (Luo et al., 1991; Martin et al., 1987a), transposable elements (Coen and Carpenter, 1986; Luo et al., 1991; Martin et al., 1987b), identification of mutations, and gene mapping (Harte, 1974). Transformation of A. majus would assist advancement of these studies and provide opportunities for commercial crop improvement. Lack of a good adventitious shoot regeneration system has hindered such advancement. Varying success with micropropagation of $A$. majus has been achieved using explants from internodes, nodes, shoot tips, and roots (Atkinson et al., 1989; Gonzalez-Benito et al., 1996; Pfister and Widholm, 1984; Sangwan and Harada, 1975); best results were obtained with explants from seedling shoot tips or hypocotyls (Atkinson et al., 1989; GonzalezBenito et al., 1996; Okuboet al., 1991; Sangwan and Sangwan, 1990).

In vitro adventitious shoot formation on hypocotyls of various species can be influ-

Received for publication 1 June 1998. Accepted for publication 16 Dec. 1998. Use of trade names does not imply endorsement of the products named or criticism of similar ones not named. Research was supported by USDA funds, project number 3861 . The cost of publishing this paper was defrayed in part by the payment of page charges. Under postal regulations, this paper therefore must be hereby marked advertisement solely to indicate this fact. ${ }^{1}$ Graduate Research Assistant.

${ }^{2}$ Professor; to whom reprint requests should be addressed. enced by photoperiod during germination and growth (Ramirez-Malagon and Ochoa-Alejo, 1996), seedling age at excision (RamirezMalagon and Ochoa-Alejo, 1996; Yang et al., 1991), and BA concentration (Calvo and Sequra, 1988; Kameya and Widholm, 1981; Yang et al., 1991). In A. majus, the effects of different germination and growth photoperiods, hypocotyl ages at excision, and BA concentrations in the culture medium have been evaluated for adventitious shoot formation, but studies to optimize shoot formation are lacking. In addition, very few genotypes were evaluated in previous studies. In this study, we investigated BA concentration, seedling age, genotype, and response to light on in vitro adventitious shoot formation on excised hypocotyls of A. majus.

\section{Materials and Methods}

General protocol. Seeds of A. majus were disinfested by stirring for $12 \mathrm{~min}$ in a $30 \%$ Clorox $(1.57 \% \mathrm{NaOCl}$; Clorox Co., Oakland, Calif.) solution containing 1 drop of Tween 20 (polyoxyethylenesorbitan) per $100 \mathrm{~mL}$. Disinfested seeds were rinsed three times with sterile deionized water and sown on the surface of half-strength MS medium (Murashige and Skoog, 1962), supplemented with 0.28 mm myoinositol, $0.6 \mu \mathrm{M}$ thiamine $\mathrm{HCl}$, and $14.7 \mathrm{~mm}$ sucrose. Medium $\mathrm{pH}$ was adjusted to 5.7 prior to adding $7 \mathrm{~g} \cdot \mathrm{L}^{-1}$ Difco Bacto agar and autoclaving $30 \mathrm{~min}$ at $120^{\circ} \mathrm{C}$ and $104 \mathrm{kPa}$. with $80 \mathrm{~mL}$ of medium were used. Germination and seedling growth occurred in a growth chamber at $25{ }^{\circ} \mathrm{C}$ under a 16 -h photoperiod provided by cool-white fluorescent light (30 $\left.\mu \mathrm{M} \cdot \mathrm{m}^{-2} \cdot \mathrm{s}^{-1}\right)$ or in continuous darkness, henceGA-7 containers (Magenta Corp., Chicago) forth called light or dark environments, respectively. Seedlings were decapitated 2 to 3 $\mathrm{mm}$ below the shoot apex, and the apical $1-\mathrm{cm}$ section of the remaining hypocotyl was excised and used as the explant in all experiments. Explants were placed in a horizontal position on the surface of MS medium, supplemented with $0.56 \mathrm{~mm}$ myoinositol, $1.2 \mu \mathrm{M}$ thiamine $\mathrm{HCl}$, and $88 \mathrm{~mm}$ sucrose (basal medium), amended with BA as required for individual experiments, prepared and dispensed as described above. Cultured hypocotyls were maintained in a growth chamber in the light environment described above.

$B A$ concentration and seedling environment. Hypocotyls of A. majus Inbred 2 (PanAmerican Seed, West Chicago, Ill.) were excised at $14 \mathrm{~d}$ from seedlings grown in the light or dark environments described above and cultured on basal medium amended with $0,0.44,2.22,4.44,8.88$, or $44.4 \mu \mathrm{M}$ BA. Adventitious shoots were counted after 2 weeks of culture. A shoot was counted if it developed a stem and at least one leaf.

Genotype. Seed from A. majus 'Cheyenne', 'Chicago', 'Floral Carpet Pink', 'Madame Butterfly', 'Pink Sprite', 'Potomac Yellow', 'Rocket White', 'Tampico'; Inbreds 1, 2, and 3 ; and the $\mathrm{F}_{1}$ hybrid between Inbreds 2 and 3 were grown in the light environment described previously. Hypocotyls were excised at $14 \mathrm{~d}$ and cultured on basal medium amended with $2.22 \mu \mathrm{M}$ BA. This level of BA was based on results from the previous experiment. Adventitious shoots were counted after 2 and 3 weeks of culture.

Hypocotyl age and seedling environment. Hypocotyls were excised from light- and darkgrown Inbred 2 seedlings at 6, 10, 14, 18, 22, 26 , or $30 \mathrm{~d}$ after seed sowing and cultured on basal medium amended with $2.22 \mu \mathrm{M}$ BA. Explants were not taken from 6-d-old seedlings grown in the light environment due to inadequate hypocotyl length. Total hypocotyl length was recorded for the shortest and tallest seedling at each explant excision date. Adventitious shoots were counted after 2 weeks of culture.

Experimental design. Completely random designs with six replications per treatment and five hypocotyls per replication (GA-7 container) were used for all studies. Data were analyzed using the General Linear Models Procedure (SAS Institute, Cary, N.C.).

Table 1. Analysis of variance for influence of seedling environment and BA concentration on adventitious shoot formation on excised hypocotyls of Antirrhinum majus cultured in vitro for 2 weeks.

\begin{tabular}{lrc}
\hline \hline Source of variation & df & Mean square \\
\hline Seedling environment $(\mathrm{E})^{\mathrm{z}}$ & 1 & $1119.7121^{\text {******}}$ \\
BA concentration & 5 & $363.2982^{\text {*****}}$ \\
E $\times$ BA & 5 & $117.4364^{\text {***** }}$ \\
Plot (box) error & 60 & $10.7290^{\text {Ns }}$ \\
Subsampling error & 287 & 8.1589 \\
\hline
\end{tabular}

zTwo-week period of light or dark from seed sowing to hypocotyl excision.

Ns, *****Nonsignificant or significant at $P \leq 0.0001$. 


\section{Results and Discussion}

BA concentration and seedling environment. Adventitious shoot formation on Inbred 2 hypocotyls was affected significantly by the interaction of seedling environment $(\mathrm{E}) \times \mathrm{BA}$ concentration (Table 1). However, the pattern of response to BA concentration was similar regardless of seedling growth environment (Fig. 1A). Mean shoots per hypocotyl ranged from 2.4 to 6.1 and 2.2 to 10.9 when hypocotyls originated from seedlings grown in dark and light environments, respectively. Shoot formation was lowest at 0 and $44.4 \mu \mathrm{M} \mathrm{BA}$ with virtually no difference between dark- and light-grown seedlings. From 0.44 to $8.88 \mu \mathrm{M}$ BA, the magnitude of increase was greater on sections from light-grown than from darkgrown seedlings. Shoot formation in light was highest at 2.22, 4.44, and $8.88 \mu \mathrm{M}$ BA. Variation among BA concentrations for shoot formation was due primarily to differences in magnitude of response to growth environment. When averaged over BA concentrations, growth in the light nearly doubled shoot formation (Fig. 1B). Shoot formation, averaged over growth environments, was highest on media containing from 2.22 to $8.88 \mu \mathrm{M} \mathrm{BA}$ (Fig. 1C) and shoots formed along the entire length of explants (Fig. 2). However, at 8.88 $\mu_{\mathrm{M}} \mathrm{BA}$, shoots were smaller, slightly vitreous, chlorotic, and formed callus. Thus, at BA concentrations above $4.44 \mu \mathrm{M}$ hypocotyls responded unfavorably. Number of shoots per hypocotyl in our study exceeded previous studies by up to 5 -fold, probably because younger hypocotyls (Atkinson et al., 1989; GonzalezBenito et al., 1996) and a different plant growth regulator (Atkinson et al., 1989) were used.

Genotype. Genotype $(\mathrm{G}) \times$ duration $(\mathrm{D})$ interaction was significant (Table 2). Shoot formation increased from week 2 to week 3 for all genotypes, but the magnitude of increase was not consistent among genotypes (Fig. $3 \mathrm{~A})$. Generally, a 2-fold increase in shoot formation occurred from week 2 to week 3 (Fig. 3B). Adventitious shoot formation proved to be genotype-dependent as previously suggested (Atkinson et al. 1989; Pfister and Widholm, 1984; Sangwan and Sangwan, 1990). For example, Inbred 1 averaged 8.4 shoots per hypocotyl while Inbred 3 averaged 0.1 (Fig. 3C). An overall average of 5.3 adventitious shoots per hypocotyl formed on 12 accessions, but shoot formation on individual hypocotyls ranged from 0 to 30 . The ability to produce adventitious shoots on hypocotyls of A. majus in vitro appears to be a dominant trait. Evidence of dominance comes from Inbred 2 (6.8 adventitious shoots) $\times$ Inbred 3 (0.2 adventitious shoots) and the $F_{1}$ hybrid producing 4.3 adventitious shoots at 3 weeks of age (Fig. 3A): a +0.8 deviation from the midparent value. This observation resembles results from Cucumis melo L. (Molina and Nuez, 1996), Lycopersicon esculentum Mill. and Lycopersicon peruvianum (L.) Mill. (Koornneef et al., 1987), diploid Medicago sativa L. (Reisch and Bingham, 1980), and Zea mays L. (Duncan et al., 1985). Several studies suggest that two dominant major genes con-
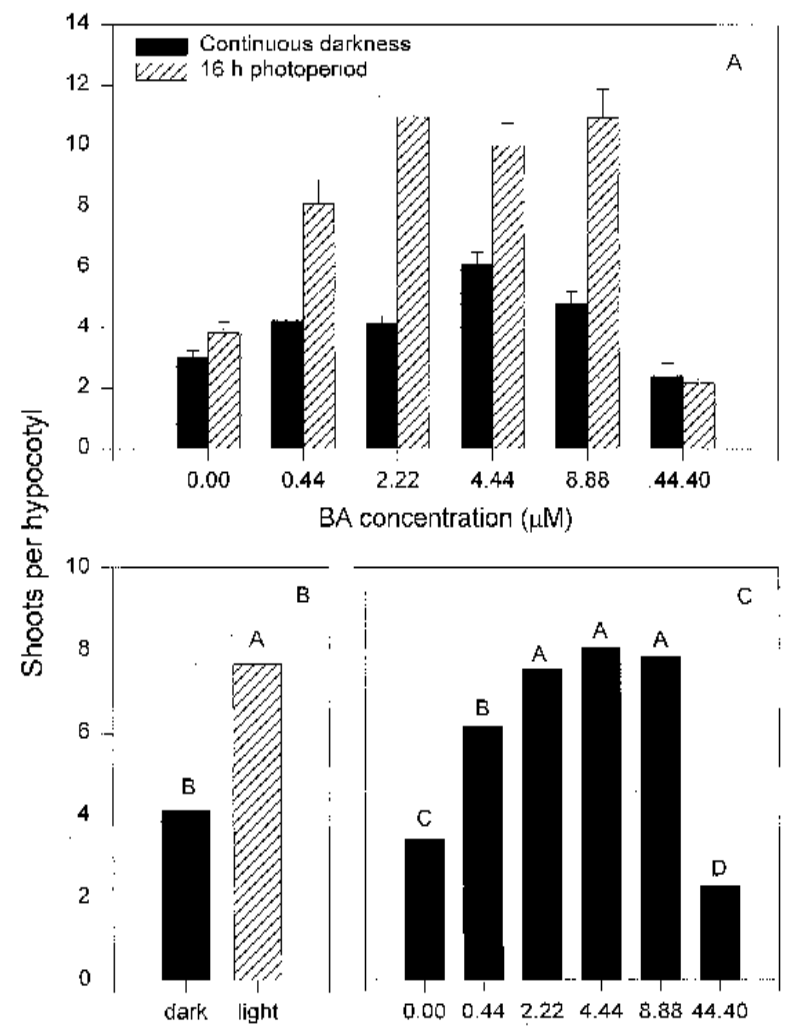

Seedling emvironment

BA concentration ( $\mu \mathrm{M})$

Fig. 1. Adventitious shoot formation in vitro on excised hypocotyls of A. majus as influenced by: (A) BA concentration and seedling environment (16-h photoperiod or continuous darkness); (B) seedling environment; and (C) BA concentration. Error bars represent \pm SE. Mean separation by LSD $_{0.05}$.

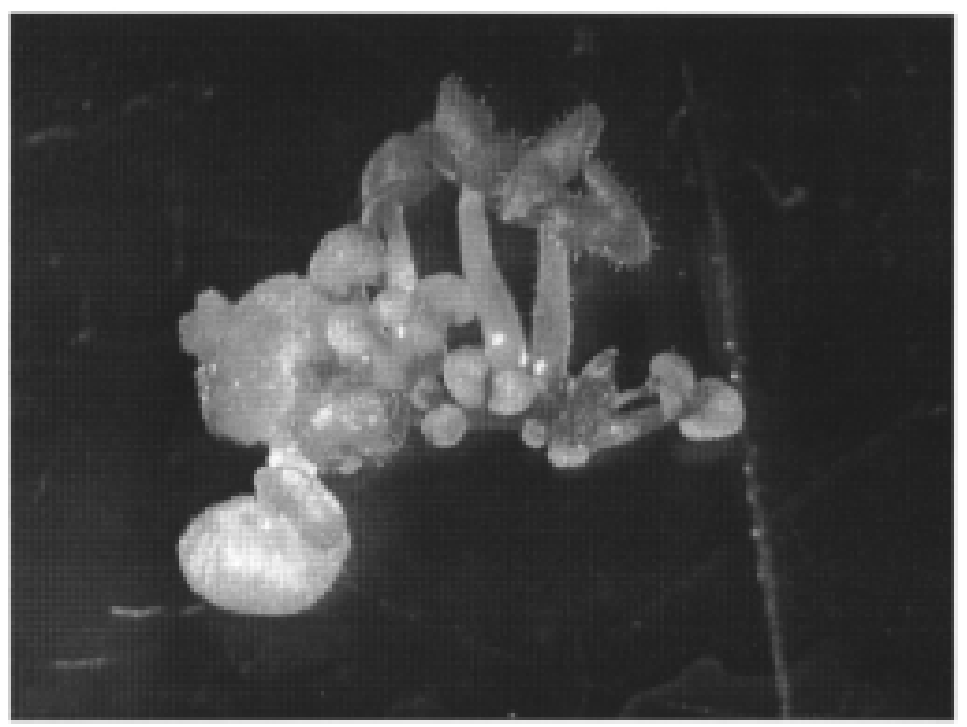

Fig. 2. Adventitious shoot formation in vitro on excised hypocotyls of A. majus cultured for 2 weeks on modified MS medium containing $2.22 \mu \mathrm{M}$ BA.

Table 2. Analysis of variance for influence of genotype and duration of culture on BA on adventitious shoot formation on excised hypocotyls of Antirrhinum majus cultured in vitro.

\begin{tabular}{lrc}
\hline \hline Source of variation & df & Mean square \\
\hline Genotype (G) & 11 & $250.9598^{* * * *}$ \\
Duration (D) & 1 & $1149.3761^{* * * *}$ \\
G $\times$ D & 11 & $25.7945^{*}$ \\
Plot (box) error & 112 & $11.7479^{\text {ns }}$ \\
Subsampling error & 544 & 10.9103 \\
\hline
\end{tabular}

$\overline{\text { ns, },{ }^{*}, * * *}$ Nonsignificant or significant at $P \leq 0.05$ or 0.0001 , respectively. 


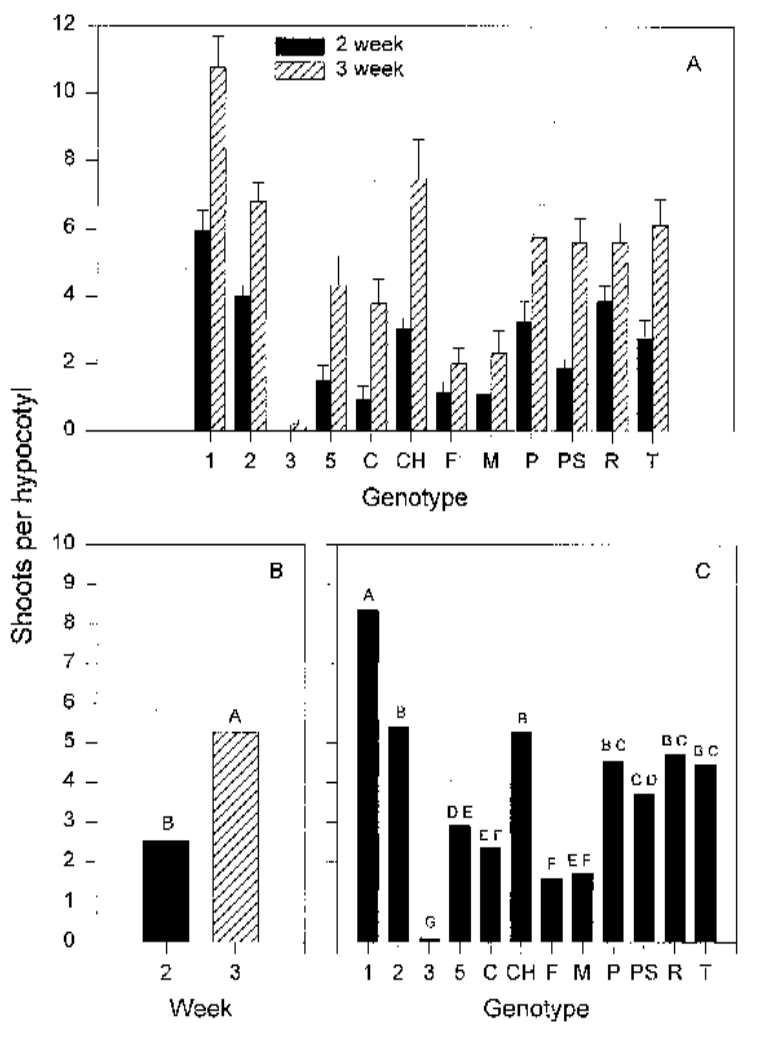

Fig. 3. Adventitious shoot formation in vitro on excised hypocotyls of A. majus as influenced by: (A) genotype ( $1=$ Inbred 1, $2=$ Inbred 2, $3=$ Inbred 3, 5 = hybrid of Inbred $2 \times$ Inbred $3, \mathrm{C}=$ 'Chicago', $\mathrm{CH}=$ 'Cheyenne', $\mathrm{F}=$ 'Floral Carpet Pink', $\mathrm{M}=$ 'Madame Butterfly', $\mathrm{P}$ = 'Potomac Yellow', PS = 'Pink Sprite', $\mathrm{R}=$ 'Rocket White', and $\mathrm{T}=$ 'Tampico') and duration cultured on BA (2 weeks or 3 weeks); (B) duration cultured on BA; and (C) genotype. Error bars represent $\pm \mathrm{SE}$. Mean separation by $\mathrm{LSD}_{0.05}$.
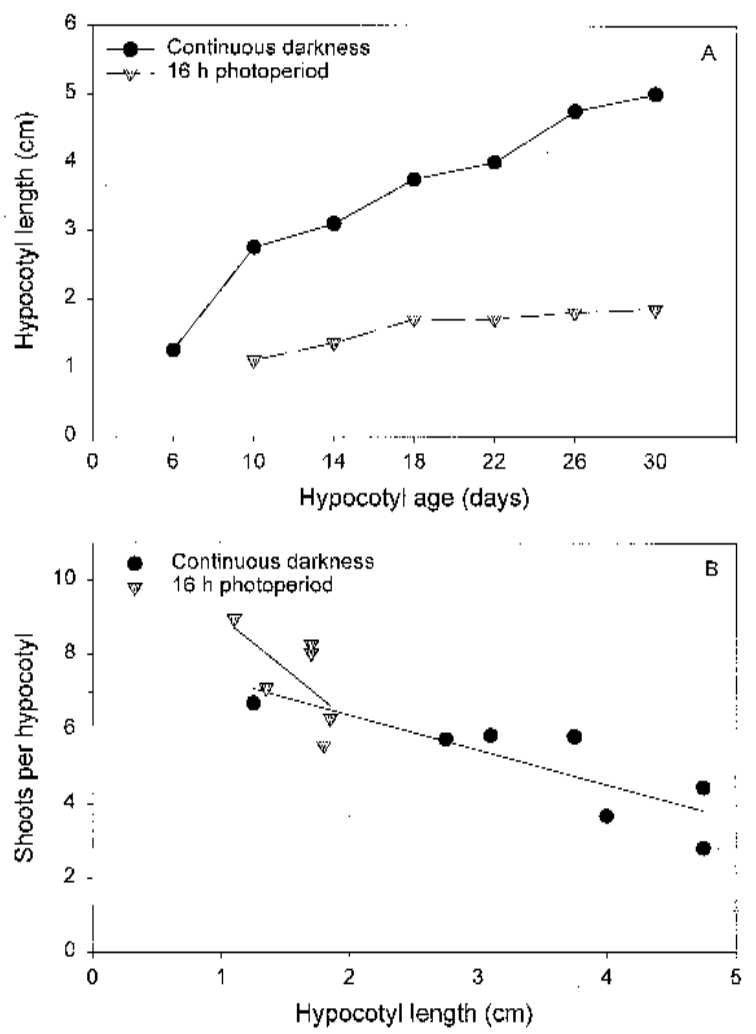

Fig. 5. Hypocotyl length in vitro of A. majus: (A) as influenced by seedling environment (16-h photoperiod or continuous darkness) and hypocotyl age, and $(\mathbf{B})$ as correlated with shoots per hypocotyl grown under 16-h photoperiods or continuous darkness.
Table 3. Analysis of variance for influence of seedling environment and hypocotyl age on adventitious shoot formation on excised hypocotyls of Antirrhinum majus cultured in vitro for 2 weeks.

\begin{tabular}{lcc}
\hline Source of variation & df & Mean square \\
\hline Seedling environment $(\mathrm{E})^{\mathrm{z}}$ & 1 & $637.3361^{* * * * *}$ \\
Hypocotyl age (A) & 6 & $76.6904^{* * * *}$ \\
E $\times$ A & 5 & $27.7561^{\text {Ns }}$ \\
Plot (box) error & 65 & $15.6451^{\text {**** }}$ \\
Subsampling error & 312 & 8.5359 \\
\hline
\end{tabular}

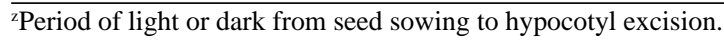

${ }^{\mathrm{y}}$ Mean square used for all F-tests.

Ns, ***,*****Nonsignificant or significant at $P \leq 0.001$ or 0.0001 , respectively.
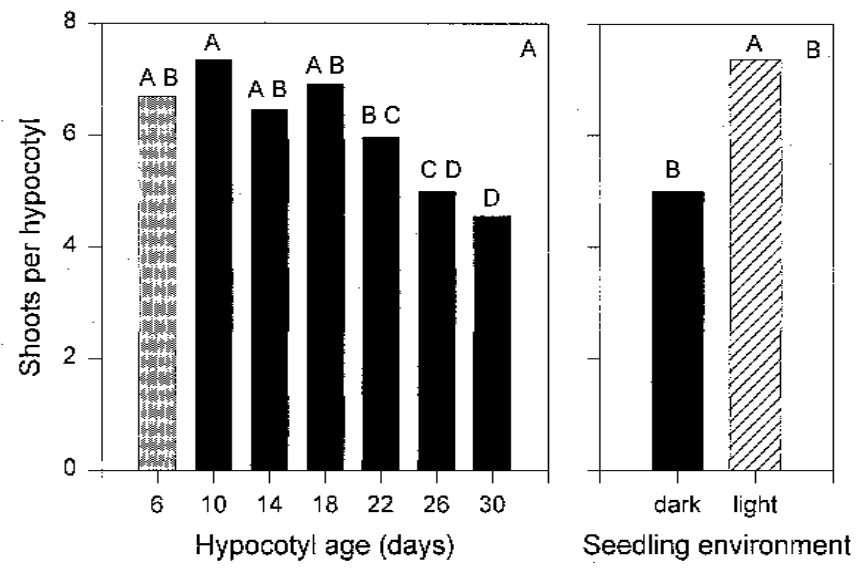

Fig. 4. Adventitious shoot formation in vitro on excised hypocotyls of A. majus as influenced by: (A) hypocotyl age and (B) seedling environment (16-h photoperiod or continuous darkness). Data for 6-dold hypocotyls are means for dark-grown seedlings only. Mean separation by $\operatorname{LSD}_{0.05}$. trol regeneration (Koornneef et al., 1987; Molina and Nuez, 1996; Reisch and Bingham, 1980). Further study is needed to develop an inheritance model for in vitro shoot formation on excised hypocotyls of $A$. majus.

Hypocotyl age and seedling environment. There was a significant effect of hypocotyl age and seedling environment on adventitious shoot formation on Inbred 2 hypocotyls, but the interaction was nonsignificant (Table 3). Regression analysis for hypocotyl age indicated the data fit a linear model $(P \leq 0.001)$, but not quadratic or cubic models. Shoot formation was highest on 6- through 18-d-old hypocotyls, with a steady decline as age increased (Fig. 4A). Kameya and Widholm (1981) reported similar results with Glycine canescens F.J. Herm hypocotyls. Mean shoot formation was higher on hypocotyls from seedlings grown in light than in dark (Fig. 4B). Our results indicate that position of the explant relative to the root contributes to reduced shoot formation on dark-grown seedling hypocotyls. Over the 30-d period, hypocotyls reached a length of $5 \mathrm{~cm}$ in the dark vs. $2 \mathrm{~cm}$ in the light (Fig. 5A). As hypocotyls lengthened, explants were excised from locations progressively more distant from the roots. A significant negative correlation $(r=-0.85, P=0.0146)$ was observed between adventitious shoot formation and hypocotyl length of seedlings grown in the dark (Fig. 5B). No correlation existed if seed- 
lings were grown in the light $(r=-0.636, P=$ 0.1746). Okubo et al. (1991) also found $A$. majus hypocotyls excised from near the root formed more shoots than those from near the cotyledons. Whether reduced shoot formation on older excised hypocotyls is influenced by reduced levels of endogenous cytokinins, reduced sensitivity to exogenous cytokinins, reduced totipotency, and/or fewer cells per hypocotyl section remains unknown.

In subsequent work, adventitious shoots from hypocotyls cultured in vitro on $2.22 \mu \mathrm{M}$ BA medium rooted readily on MS medium amended with $0.5 \mu \mathrm{M}$ indole-3-butyric acid and grew into normal fertile plants (data not presented).

In conclusion, seedling environment, BA concentration, hypocotyl age, and genotype influenced the number of adventitious shoots formed on excised hypocotyls of A. majus. Optimal shoot formation resulted when seedlings were grown in a 16-h photoperiod, hypocotyls were excised from 10-d-old seedlings, the medium was amended with $2.22 \mu \mathrm{M}$ BA, and cultures were maintained for 3 weeks. Future work should determine the possibility of using this improved regeneration protocol to recover transgenic plants. The wide range of shoot formation observed among cultivars and the speculated dominant gene action controlling adventitious shoot formation warrant further study.

\section{Literature Cited}

Atkinson, N.J., B.V. Ford-Lloyd, and H.J. Newbury. 1989. Regeneration of plants from Antirrhinum majus L. callus. Plant Cell Tiss. Org. Cult. 17:59-70.

Calvo, M.C. and J. Segura. 1988. In vitro morphogenesis from explants of Lavandula latifolia and Lavandula stoechas seedlings. Scientia Hort. 36:131-137.

Coen, E.S. and R. Carpenter. 1986. Transposable elements in Antirrhinum majus: Generators of genetic diversity. Trends Genet. 2:292-296.

Coen, E.S., J.M. Romero, S. Doyle, R. Elliot, G. Murphy, and R. Carpenter. 1990. Floricaula: A homeotic gene required for flower development in Antirrhinum majus. Cell 63:1311-1322.

Duncan D.R., M.E. Williams, B.E. Zehr, and J.M. Widholm. 1985. The production of callus capable of plant regeneration from immature embryos of numerous Zea mays genotypes. Planta 165:322-332.

Gonzalez-Benito, M.E., J. Tapia, N. Rodriguez, and J.M. Iriondo. 1996. Micropropagation of commercial and wild genotypes of snapdragon ( $\mathrm{An}$ tirrhinum spp.). J. Hort. Sci. 71:11-15.

Harte, C. 1974. Antirrhinum majus L., p. 315-331. In: R.C. King (ed.). Handbook of genetics. Plenum Press, New York.

Kameya, T. and J. Widholm. 1981. Plant regeneration from hypocotyl sections of Glycine species. Plant Sci. Lett. 21:289-294.

Koornneef, M., C.J. Hanhart, and L. Martinelli. 1987. A genetic analysis of cell culture traits in tomato. Theor. Appl. Genet. 74:633-641.

Luo, D., E.S. Coen, S. Doyle, and R. Carpenter. 1991. Pigmentation mutants produced by transposon mutagenesis in Antirrhinum majus. Plant J. 1:59-69.

Martin, C., E.S. Coen, T. Robbins, J. Bartlett, J. Almeida, and R. Carpenter. 1987a. The control of floral pigmentation in Antirrhinum. Biochem. Soc. Trans. 15:14-17.

Martin, C., R. Carpenter, T. Robbins, A. Hudson, J.
Almeida, J. Bartlett, S. MacKay, and E.S. Coen. 1987b. Transposable elements in Antirrhinum majus. J. Cell Sci. 7:109-122.

Molina, R.V. and F. Nuez. 1996. The inheritance of organogenic response in melon. Plant Cell Tiss. Org. Cult. 46:251-256.

Murashige, T. and F. Skoog. 1962. A revised medium for rapid growth and bioassays with tobacco tissue culture. Physiol. Plant. 15:473-497.

Okubo, H., K. Wada, and S. Uemoto. 1991. In vitro morphogenetic response and distribution of endogenous plant hormones in hypocotyl segments of snapdragon (Antirrhinum majus L.). Plant Cell Rpt. 10:501-504.

Pfister, J.M. and J.M. Widholm. 1984. Plant regeneration from snapdragon tissue cultures. Hort. Sci. 19:852-854.

Ramirez-Malagon, R. and N. Ochoa-Alejo. 1996. An improved and reliable chili pepper (Capsicum annиum L.) plant regeneration method. Plant Cell Rpt. 16:226-231.

Reisch, B. and E.T. Bingham. 1980. The genetic control of bud formation from callus cultures of diploid alfalfa. Plant Sci. Lett. 20:71-77.

Sangwan, R.S. and H. Harada. 1975. Chemical regulation of callus growth, organogenesis, plant regeneration, and somatic embryogenesis in $\mathrm{An}$ tirrhinum majus tissue and cell cultures. J. Expt. Bot. 26:868-881.

Sangwan, R.S. and J.S. Sangwan. 1990. Snapdragon, p. 744-762. In: P.V. Ammirato, D.A. Evans, W.R. Sharp, and Y.P.S. Bajaj (eds.). Handbook of plant cell culture. Vol. 5. Ornamental species. Springer-Verlag, New York.

SAS Institute. 1990. SAS/STAT user's guide. Ver. 6.09. 44th ed. Vol.2. SAS Inst., Cary, N.C.

Yang, M., S. Jia, and E. Pua. 1991. High frequency of plant regeneration from hypocotyl explants of Brassica carinata A. Br. Plant Cell Tiss. Org. Cult. 24:79-82. 